\title{
Enhancing the Assessment of Cleaner Production Practices for Sustainable Development: The Five Sectors Sustainability Model Applied to Water and Wastewater Treatment Companies
}

\author{
Biagio F. Giannetti 1,4,*, Fábio Sevegnani 1, Roberto R.M. García ${ }^{2}$, Feni Agostinho ${ }^{1,4}$, Cecília M.V.B. Almeida 1,4, \\ Luca Coscieme ${ }^{3}$, Genguyan Liu ${ }^{4,5}$ and Ginevra Virginia Lombardi ${ }^{6}$ \\ 1 Programa de Pós-Graduação em Engenharia de Produção, Paulista University, Sao Paulo, Brazil \\ 2 Universidad de Oriente, Santiago de Cuba, Cuba \\ 3 Hot or Cool Institute, Germany \\ 4 School of Environment, Beijing Normal University, China \\ 5 Beijing Engineering Research Center for Watershed Environmental Restoration \& Integrated Ecological \\ Regulation, China \\ 6 Dipartimento di Scienze per l'Economia e l'Impresa, University of Florence, Italy \\ * Correspondence: bfgian@unip.br; Tel.: +55 1155864127
}

\begin{abstract}
Water resources are under pressure because of human activities. Its management faces the challenge of enhancing long-term water security while minimizing undesirable economic, social, and environmental impacts along with its production chain. Since water and wastewater treatment plants are designed to maintain and conserve freshwater provisioning services, it is paramount to understand how it operates before proposing options for sustainability. At this point, the diagnosis phase claims for methods scientifically-based, systemic, and more objective to provide information for decision-makers towards strategic management of water resources. This work applies the fivesector sustainability model (5SenSu) to assess Brazil's twenty major water and wastewater treatment companies (WWTC) to quantify their sustainability levels that allow ranking procedures and the establishment of benchmarks for improvements. Under comparative basis, results identified the top-three sustainable companies, CORSAN, CASAN, and SANEPAR, which should be considered examples of best practices. Specifically, the following best-ranked companies in each sector within 5SenSu should be used as benchmark patterns for more oriented best practices: SANEAGO, sector 1; AGESISA, sector 2; CORSAN, sector 3; CASAL, sector 4; MA, sector 5. This work contributes to the advancement in modeling sustainability assessment of human-managed systems (applied in WWTCs in this present study) from a systemic and epistemologically rooted approach, avoiding shortcomings and misleading discussions on the sustainability issue. Quantifying sustainability of WWTCS from 5SenSu allows the identification of those sectors/indicators that requires immediate cleaner production practices by decision-makers to improve overall sustainability, besides identifying those companies more aligned with the requirements of UN SDGs.
\end{abstract}

Keywords: Sustainability model; SDGs; clean water; drinking water; water security

\section{Introduction}

Population growth, economic development, and urbanization are pressuring the world's water resources. Worldwide, governments face ongoing challenges in enhancing water security for increasingly urbanized populations and how to replace, assist and/or complement naturally occurring and functioning systems with highly human-engineered systems or, preferably, nature-based solutions. Additionally, it is essential to recognize that natural ecosystems also need water to develop their biological processes. However, Postel (2003) highlights the limited knowledge and understanding of how complex 
ecosystems behave at different scales under the stresses of changing patterns of water availability and increasing water demand.

Perhaps, more than any other natural resource, water intersects with all parts of the natural environment and society, and it is indispensable for producing food and converting energy. Clean water contributes to human wellbeing and welfare (De Jongh et al., 2019), thus better understanding how the water and wastewater treatment companies (WWTC) deal with this natural capital would help to improve the management and design of water supply/treatment systems by adopting water conservation technologies (Woodhouse, 2012) and cleaner production practices. Healthy natural ecosystems can maintain their structures and functions while generating several ecosystem services (Huttenhower et al., 2012), which calls attention to developing more sustainable water supply/treatment plants to protect ecosystems and their services. To achieve this important goal, there is a need to develop reliable assessment methods that express sustainability to ensure reliable decision-making.

In 2015, the United Nations sustainable development goals (SDGs) included several global clean water and sanitation targets in its $6^{\text {th }}$ goal, highlighting the relevance of clean water access for achieving environmental, social, and economic sustainability (UN, 2015). It is expected that in 2050 the global demand for clean water will increase by $55 \%$, and the world's water supply will have to support additional 2.7 billion people consuming from 2 to 4 liters per person for daily drinking and from 2,000 to 5,000 liters to produce one person's daily food UN (2014). Meeting human needs for water provisioning services of domestic use, irrigation, and industrial use requires the exploitation of water ecosystems. The main challenge is to deal with these different demands by managing water resources and applying existing cleaner technologies and tools to related processes (including capture, pumping, filtration, biological sanitation, etc.) to increase the productivity and security of water for societal development.

To obtain water suitable for consumption and/or water legally accepted for natural dilution into rivers, WWTCs require the investment of renewable and non-renewable resources and the construction of WWT plants, and it generates by-products direct or indirect or indirect indirectly. Thus, the target is to choose those WWTC that cause a lower load on the environment and provide the same amount and quality of water for human use. For this purpose, multicriteria decision-making techniques have been applied to study WWTC systems from different perspectives (Nematian and Movahhed, 2019; Marques et al., 2015). Specifically, Molinos-Senante et al. (2016) proposed a multidimensional synthetic indicator based on economic, environmental, and social criteria. They used it on 154 water treatment companies in Portugal to benchmark the sector and help decision-makers identify the more efficient provision of urban water services.

Regarding resource use, emergy analysis (with an ' $\mathrm{m}$ ') was used for sustainability assessments of water treatment plants (Zhang et al., 2010; Liu et al., 2015), the greenhouse gas emissions were estimated for water infrastructure (Zhang et al., 2015), and cleaner production measures were implemented to reach energy and materials savings (Zhang et al., 2019). Focusing on materials consumption and carbon emissions, Giannetti et al. (2013) applied emergy-based indices to assess the sustainability of two alternative domestic wastewater treatment processes. Other studies had a different focus, as the discussion of uncertainties and trade-offs when implementing water and wastewater treatment projects (Mirabia et al., 2014), the use of material and energy resources for new projects (Vassallo et al.; 2009), and technical aspects behind the generation of electricity by sewage sludge digestion (Björklund et al., 2001).

Concerning the need to identify and develop more sustainable approaches to technically manage WWTCs and looking for mechanisms to improve the existing ones, this paper explores the strangeness of 5SEnSU when applying to Brazilian WWTCs. The main goal is to provide evidence about the importance of using a multidimensional approach to improve decision-making on what cleaner production practices should be applied to reinforce the natural capital sustaining water availability. More than a simple diagnosis, 
this study identifies those more sustainable WWT companies and provide, comparatively, actions to increase the performance for those with lower performance. This is an essential contribution for policymakers in water supply and treatment management.

\section{Methods}

\subsection{Systems description and data collection}

To achieve the proposed initial goals, case studies are of paramount importance. Data from Brazilian WWTCs are used to highlight the proposed procedure's strengths. Anyhow, any WWTC from other regions worldwide could be considered for analysis. Data were collected from National Information System on Sanitation (SNIS, 2018). According to 2014 data, which is the most updated and available values, there were more than 1,500 WWTCs in Brazil, from which the 20 largest ones were selected based on the population served. Figure 1 shows a schematic representation of the WWTCs evaluated, highlighting the established boundaries, inputs, and outputs of energy, material, and labor to treat water for potable purposes and the sewage for further natural dilution. Important to say that all WWTCs evaluated have both functions, to obtain potable water and less concentrated sewage.

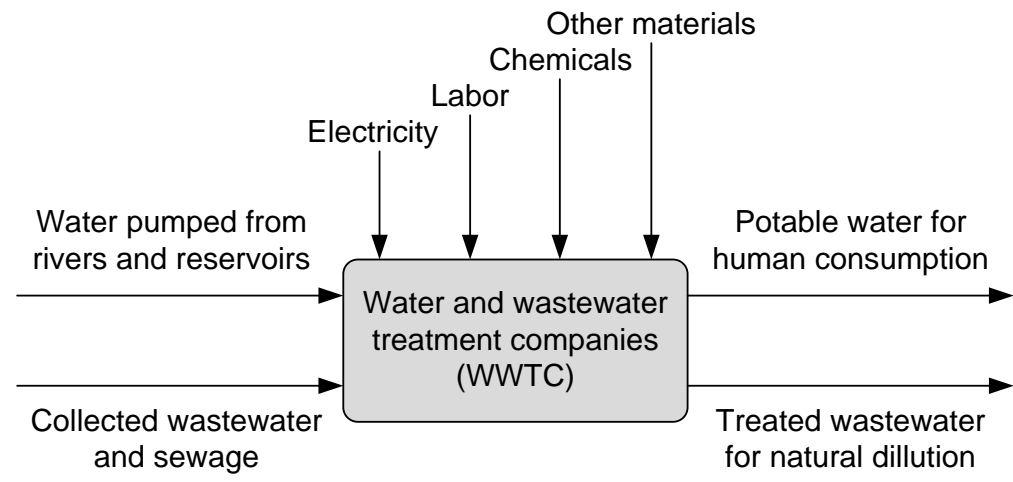

Figure 1. Schematic representation for the evaluated WWT companies.

2.2. Modelling water resources management and its relationship with environmental, economic, and social capitals

Unlike other studies that failed in structuring their sustainability assessment under strong construct bases, the 5SenSu model (Figure 2) was proposed by Giannetti et al. (2019) to assess sustainability by considering five sectors with a designated function. The model comes from the well-known input-state-output sustainability model, including the three crucial capitals when dealing with sustainability discussions. The 5SenSu model clarifies that all production systems, whether natural or human-made, belong to a larger, complex, and integrated system. When applied to WWTCs, the 5SEnSU model sectors are environment as the provider of resources (source function, sector 1), environment as the receiver of residues (waste and pollutants; drain function, sector 2), the economic and efficiency aspects of WWTCs (production function, sector 3), society providing resources (materials and labor; supplier function, sector 4), and society receiving products (treated water; consumption function, sector 5). 


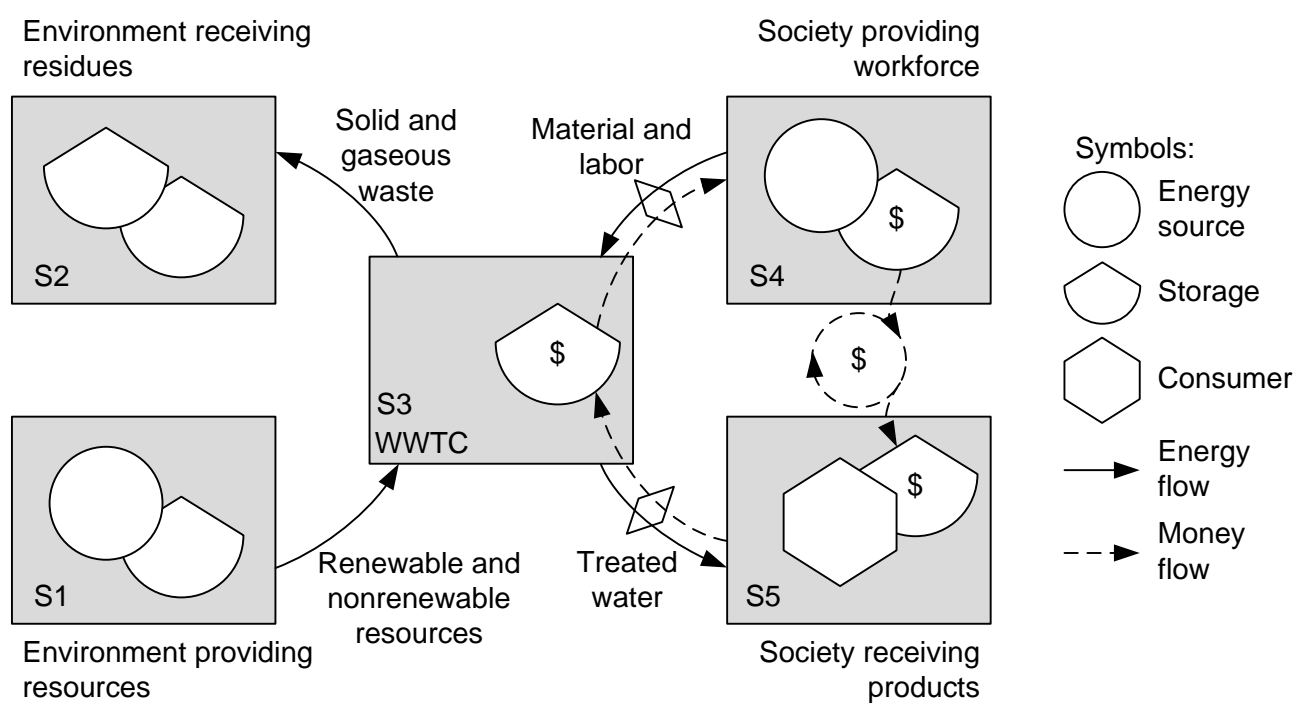

Figure 2. The five sectors sustainability model (5SenSu) adapted from Giannetti et al. (2019). $S=$ sector; $\mathrm{WWTC}=$ water and wastewater treatment company.

The environment in sector 1 provides renewable or non-renewable raw materials that support the WWTCs represented by sector 3 . The environment in sector 2 receives wastes and emissions generated by the production unit. Society in sector 4 also holds a double function because it supplies socioeconomic resources such as manufactured materials, labor, and know-how to the production unit, receiving money as a counterpart. The production unit supplies treated water for society at a given economic cost (dashed arrow). Monetary flows are only considered for activities involving the society and the production unit since the trade of energy and matter with the environment are viewed as free of charge (Giannetti et al., 2019).

According to the procedures suggested for using the $5 \mathrm{SenSu}$ as available in Giannetti et al. (2019), ten indicators were selected (two per sector) to feed the model according to experts' interpretation of their representativeness on the studied systems (WWTCs) and data availability. Indicators are referred by the letter K, followed by a number indicating the 'macro-sector' ( 1 for the environment as a provider, 2 for the environment as receiver, 3 for the WWTCs, 4 for the society as a provider, and 5 for the society as receiver), and a second number indicating the number of indicator for the same sector (in this case 1 and 2 because two indicators per sector were chosen). According to its importance when discussing sustainability issues, the relationships of each indicator feeding the 5SenSu with the SDGs were also identified and considered; the identification is based on information provided by Giannetti et al. (2020) and the author's expertise in the subject. The following section presents the chosen indicators used in the 5SenSu in detail, separating them into environmental, economic, and social sectors.

\subsubsection{Environmental indicators}

The chosen indicators for sector 1 representing the natural environment as a provider were the percentage of loss of potable water through leakage $\left(K_{11}\right)$ and the volume of water extracted per population attended $\left(K_{12}\right)$ in 1,000 m³/year person. $K_{11}$ measures the percentage of potable water lost over the total water treated through pipelines from the WWTCs to the final user. It provides an efficiency measure of the distribution system and refers to material and energy losses during potable water transportation. Usually, the highest losses are due to poor pipeline maintenance. The value of this indicator expressed as a percentage should be minimized to improve the WWTC's sustainability. The second indicator, $\mathrm{K}_{12}$ measures the volume of water extracted from natural sources such as lakes, reservoirs, or rivers expressed in thousands of cubic meters per year divided by the 
population attended by the given WWTC. The value of this indicator should be minimized, showing higher efficiency in preserving natural water sources to attend to population needs.

Concerning sector 2 that represents the natural environment as a receiver, the chosen indicators were $\mathrm{CO}_{2}$ emissions per year from electricity used during sewage treatment and the greenhouse gases (GHGs) direct released by sewage natural fermentation $\left(\mathrm{K}_{21}\right)$, in tons $\mathrm{CO}_{2}$ eq. $/ \mathrm{m}^{3}$ year, and $\mathrm{CO}_{2}$ emissions per year from electricity used during potable water treatment $\left(\mathrm{K}_{22}\right)$, in tons $\mathrm{CO}_{2} \mathrm{eq} . / \mathrm{m}^{3}$ year. $\mathrm{K}_{21}$ measures the annual greenhouse gas emissions from electricity use and sewage natural fermentation per total volume of treated sewage (Eq. 1). Emissions from sewage are calculated based on the Biochemical Oxygen Demand (BOD). $\mathrm{K}_{21}$ refers to the intensity of GHGs emissions during the treatment process, and it should be minimized to improve WWTC's sustainability.

$$
\mathrm{K}_{21}=\frac{\text { Electricity }+ \text { BOD treated sewage }+ \text { BOD non-treated sewage }}{\mathrm{V}_{\text {total sewage }}}\left(\frac{\text { ton } \mathrm{CO}_{\text {2eq }}}{\mathrm{m}^{3} \text {.year }}\right)
$$

$\mathrm{K}_{22}$ indicator represents the drinking water treatment process, which involves intensive use of electricity (UN, 2014) produced by different sources, and thus, generating different quantities of GHGs as a further embodied impact. This indicator measures the GHGs in $\mathrm{CO}_{2}$ equivalents due to electricity used in the potable water treatment process (Eq. 2), and it should be minimized to increase WWTC's sustainability.

$$
\mathrm{K}_{22}=\frac{\text { Electricity use emissions }}{\mathrm{V}_{\text {treated water }}}\left(\frac{\text { ton } \mathrm{CO}_{2 \mathrm{eq}}}{\mathrm{m}^{3} \text {.year }}\right)
$$

\subsubsection{Economic indicators}

The indicator net profit $\left(\mathrm{K}_{31}\right)$, in USD/m ${ }^{3}$, measures the gross profit of WWTCs adjusted by inflation along last seven years - since we are using 2014 data - and the volume of water and sewage processed (Eq. 3); $\mathrm{V}_{\mathrm{H} 2 \mathrm{O}}+$ sewage $=$ volume of potable or treated water and treated sewage. $K_{31}$ partially reflects the company's economic performance and should be maximized for ensuring economic maintenance over time.

$$
\mathrm{K}_{31}=\frac{\text { Net profit }}{\mathrm{V}_{\mathrm{H}_{2} \mathrm{O}+\text { sewage }}}\left(\frac{\mathrm{USD}}{\mathrm{m}^{3}}\right)
$$

The second indicator for sector 3 is gross value added $\left(\mathrm{K}_{32}\right)$, in USD/m3, a measure of productivity in terms of a company's contribution to the broader economic system (Johnston and Buchanan, 2016). As shown by Eq. 4, the K $\mathrm{K}_{32}$ indicator provides a monetary value for the amount of goods and services (gross product, GP) that have been produced minus the cost of all inputs (material costs, MC) that are directly attributable to the production

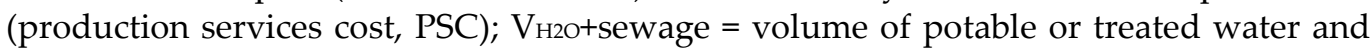
treated sewage. This indicator should be maximized for improving the company's economic performance.

$$
\mathrm{K}_{32}=\frac{\mathrm{GP}-(\mathrm{MC}+\mathrm{PSC})}{\mathrm{V}_{\mathrm{H}_{2} \mathrm{O}+\text { sewage }}}\left(\frac{\mathrm{USD}}{\mathrm{m}^{3}}\right)
$$

\subsubsection{Social Indicators}

Regarding society as a provider, the chosen indicators for sector 4 were labor use $\left(\mathrm{K}_{41}\right)$, in employees $/ \mathrm{m}^{3}$, and total salary per gross value added $\left(\mathrm{K}_{42}\right)$, dimensionless. As shown by Eq. 5, $\mathrm{K}_{41}$ measures the number of jobs in each company to reflect positive impacts on society, which should be maximized. 


$$
\mathrm{K}_{41}=\frac{\text { Total employees }}{\mathrm{V}_{\mathrm{H}_{2} \mathrm{O}+\text { sewage }}}\left(\frac{\text { employee }}{\mathrm{m}^{3}}\right)
$$

The $K_{42}$ indicator expresses the value of salaries of all company's employees per year over the gross value added divided by the volume of water and sewage (Eq. 6). Gross value added is calculated as the total expenses (USD) per volume of water plus sewage treated per year. This indicator should be maximized for improving the social welfare and sustainability of WWTCs.

$$
\mathrm{K}_{42}=\frac{\frac{\text { Total salaries }}{\text { Gross value added }}}{\mathrm{V}_{\mathrm{H}_{2} \mathrm{O}+\text { sewage }}}(\text { dimensionless })
$$

Considering the society acting as a receiver in sector 5 , the chosen indicators were water consumption per capita $\left(\mathrm{K}_{51}\right)$, in liters per person per day, and the treated to invoiced sewage $\left(K_{52}\right)$, in \%. Directly related to people's wellbeing, the $K_{51}$ measures the volume of water invoiced daily divided by the population served by the company (Eq. 7). The World Health Organization (WHO, 2020) quantifies the optimal access level to water for drinking, cooking, and hygiene purposes of more than 100 liters per capita per day. The optimal value was considered 110 liters per capita per day according to the Sanitation, Hot Water Safety Report (2010).

$$
\mathrm{K}_{51}=\frac{\mathrm{V}_{\mathrm{H}_{2} \mathrm{O}}}{\text { population*day }}\left(\frac{\mathrm{l}}{\text { person*day }}\right)
$$

The indicator $\mathrm{K}_{52}$ measures the volume of treated sewage divided by the invoiced sewage (Eq. 8) since some companies do not treat $100 \%$ of the collected sewage. This indicator should be maximized.

$$
\mathrm{K}_{52}=\frac{\mathrm{V}_{\text {treated sewage }}}{\mathrm{V}_{\text {collected sewage }}}
$$

\subsubsection{Overall view of indicators feeding the $5 \mathrm{SenSu}$}

Table 1 summarizes the ten indicators chosen to feed the five sectors model, their goals, as well their potential in contributing to one or more SDGs due to the interactions and trade-offs existing across them (Nilsson et al., 2016; Pradhan et al., 2017; Giannetti et al., 2020). According to each SDG target, the expertise of authors, and the previously obtained results from Giannetti et al. (2020), the last column of Table1 shows the identified interrelationship of chosen indicators with SGDs. Correlating the selected indicators with SDGs is an important step to show the strengths of the 5SenSu model in embracing the UN SDGs. 
Table 1. Indicators, their objectives, and goals as set to feed the 5SenSu model to assess the sustainability of the twenty largest WWTC in Brazil.

\begin{tabular}{|c|c|c|c|c|}
\hline Sector & Indicators & Objective & Goal & Related SDGs \\
\hline \multirow[b]{2}{*}{1} & $\mathrm{~K}_{11}$, the share of water lost $(\%)$ & Minimize & $\operatorname{Min}\left(K_{11}\right)+\sigma\left(K_{11}\right)$ & 6,12 \\
\hline & $\begin{array}{l}\mathrm{K}_{12} \text {, the volume of water extracted/population at- } \\
\text { tended }\left(1,000 \mathrm{~m}^{3} / \text { year person }\right)\end{array}$ & Minimize & $\operatorname{Min}\left(\mathrm{K}_{12}\right)+\sigma\left(\mathrm{K}_{12}\right)$ & $6,12,14$ \\
\hline \multirow{2}{*}{2} & $\begin{array}{r}\mathrm{K}_{21}, \mathrm{CO}_{2} \text { emissions per year from sewage } \\
\text { (tons } \mathrm{CO}_{2-\mathrm{eq}} / \mathrm{m}^{3} \mathrm{yr} \text { ) }\end{array}$ & Minimize & $\operatorname{Min}\left(\mathrm{K}_{21}\right)+\sigma\left(\mathrm{K}_{21}\right)$ & 6,13 \\
\hline & $\begin{array}{c}\mathrm{K}_{22}, \mathrm{CO}_{2} \text { emissions per year from electric energy } \\
\text { use (tons } \mathrm{CO}_{2-\mathrm{eq}} / \mathrm{m}^{3} \mathrm{yr} \text { ) }\end{array}$ & Minimize & $\operatorname{Min}\left(\mathrm{K}_{22}\right)+\sigma\left(\mathrm{K}_{22}\right)$ & 6,13 \\
\hline \multirow{3}{*}{3} & $\mathrm{~K}_{31}$, net profit $\left(\mathrm{USD} / \mathrm{m}^{3}\right)$ & Maximize & $\overline{\mathrm{K}_{31}}+\sigma\left(\mathrm{K}_{31}\right)$ & 6,8 \\
\hline & $\mathrm{K}_{32}$, gross value added $\left(\mathrm{USD} / \mathrm{m}^{3}\right)$ & Maximize & $\overline{\mathrm{K}_{32}}+\sigma\left(\mathrm{K}_{32}\right)$ & 6,8 \\
\hline & $\mathrm{K}_{41}$, labor use (employees $\left./ \mathrm{m}^{3}\right)$ & Maximize & $\overline{\mathrm{K}_{41}}+\sigma\left(\mathrm{K}_{41}\right)$ & 6,8 \\
\hline 4 & $\begin{array}{c}\mathrm{K}_{42} \text {, total salary per gross value added (dimen- } \\
\text { sionless) }\end{array}$ & Maximize & $\overline{\mathrm{K}_{42}}+\sigma\left(\mathrm{K}_{42}\right)$ & $3,6,8$ \\
\hline \multirow{2}{*}{5} & $\mathrm{~K}_{51}$, water consumption per capita (L/person day) & Maximize & $110 \mathrm{~L} /$ person day & $3,6,12$ \\
\hline & $\mathrm{K}_{52}$ treated to invoiced sewage $(\%)$ & Maximize & $\overline{\mathrm{K}_{52}}+\sigma\left(\mathrm{K}_{52}\right)$ & $3,6,14$ \\
\hline
\end{tabular}

${ }^{\text {a } n}$ SDG 3, good health and wellbeing; SDG 6, clean water and sanitation; SDG 8, decent work and economic growth; SDG 12, responsible consumption and production; SDG 13, climate action; SDG 14 , life below water.

Indicators are processed under the goal programming technique to obtain the final synthetic indicator of sustainability (SSIS) for the WWTCs evaluated (Figure 3), in which the higher the SSIS, the lower the sustainability level will be (further details in Giannetti et al., 2019). The SSIS values reflect how close the whole set of ten indicators of each WWTC is to the established goals. The goal programming applied in this study is available at Supplementary Material A in Excel ${ }^{\circledR}$ file, which can be visualized to check calculation procedures and applied in other study cases.

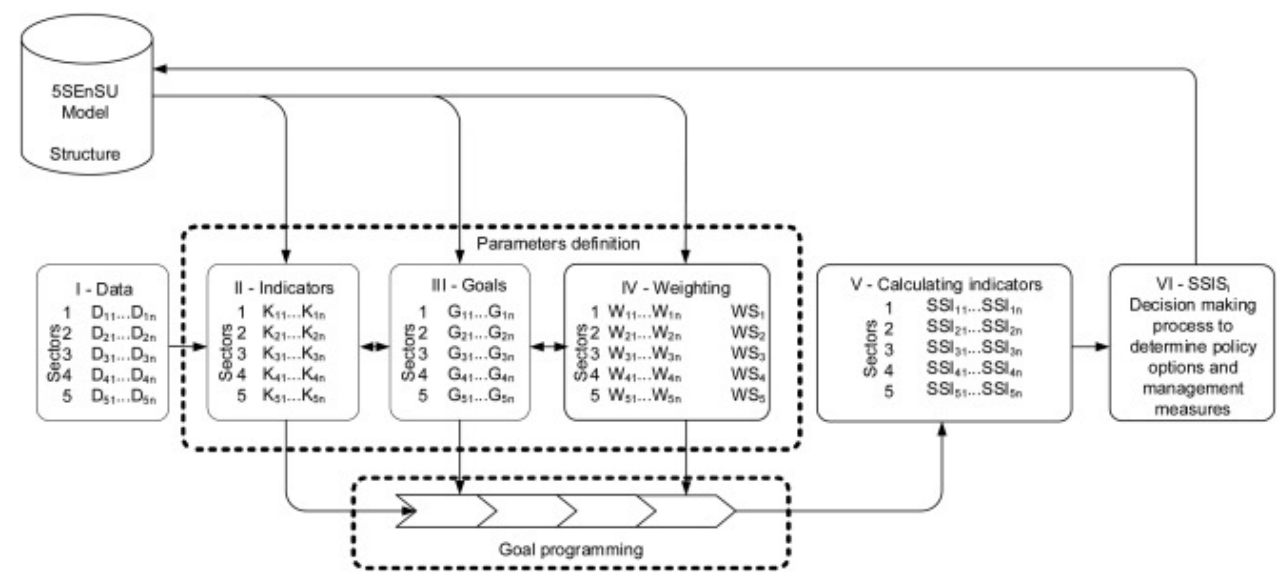

Figure 3. Procedures for the SSIS calculation using the 5 SEnSU model. D=data; $\mathrm{K}=$ indicator; $\mathrm{G}=$ goal; $\mathrm{W}$ and WS are the relative weights for each indicator; $\mathrm{SSI}=$ sector sustainability indicator; SSIS = sustainability synthetic indicator. Source: Giannetti et al., 2019.

WWTCs are firstly ranked according to their SSIS index and then labeled within one of the sustainability levels as presented by Table 2 . The established levels of high, medium, and low sustainability are set according to the SSIS obtained by the sample of WWTCs considered in this study. Thus, the comparative approach changes according to the obtained SSIS values and sample size. Although further studies are needed to establish these sustainability levels, this suggested approach (Table 2) can be considered important as a benchmark to allow comparative discussions. 
Table 2. Sustainability levels established according to the obtained SSIS.

\begin{tabular}{|c|c|}
\hline Criteria & Sustainability level \\
\hline $\begin{array}{c}\text { Minimum }_{\text {SSIS }}<\text { SSIS } \leq \overline{\text { SSIS }}-\sigma_{\text {SSIS }} \\
7.5<\text { SSIS } \leq 11.9\end{array}$ & High \\
\hline $\begin{array}{c}\overline{\mathrm{SSIS}}-\sigma_{\mathrm{SSIS}}<\mathrm{SSIS} \leq \overline{\mathrm{SSIS}}+\sigma_{\mathrm{SSIS}} \\
11.9<\mathrm{SSIS} \leq 20.9\end{array}$ & Medium \\
\hline $\begin{aligned} \overline{\mathrm{SSIS}}+\sigma_{\mathrm{SSIS}} & <\text { SSIS } \leq \text { Maximum }_{\mathrm{SSIS}} \\
20.9 & <\mathrm{SSIS} \leq 24.1\end{aligned}$ & Low \\
\hline
\end{tabular}

$\overline{\overline{\text { SSIS }}}=$ average value for SSIS; $\sigma_{\text {SSIS }}=$ standard deviation for SSIS. Values obtained from Figure 4.

\section{Results}

After running the 5SenSu model considering the chosen indicators, goals, and objectives as previously established (Appendix A), Figure 4 presents the SSIS values for the 20 largest WWTC in Brazil and their respective SSI performance in each sector. The overall SSIS value combines the indicators of a given company for all sectors. The rank of each sector (circles in Figure 4) is a comparative measure of how close the indicator's value is to the targets set through goal programming. From an overall analysis, it can be seen a high heterogeneity among the Brazilian WWTCs, highlighting their strengths (green circles) and weaknesses (red circles) that should be taken as priorities for management. As any human-driven activity, WWTCs involve economic decision-making and generate environmental impacts through direct water use and emissions. Thus, finding where actions must be applied (red circles) to improve their overall performance is paramount for more sustainable WWTCs.

\begin{tabular}{|c|c|c|c|c|c|c|c|}
\hline $\begin{array}{c}\text { Final Ranked } \\
\text { Companies }\end{array}$ & $\begin{array}{c}\text { SSIS } \\
\text { values }\end{array}$ & $\begin{array}{c}\text { Sector } \\
1\end{array}$ & $\begin{array}{c}\text { Sector } \\
2\end{array}$ & $\begin{array}{c}\text { Sector } \\
3\end{array}$ & $\begin{array}{c}\text { Sector } \\
4\end{array}$ & $\begin{array}{c}\text { Sector } \\
5\end{array}$ & $\begin{array}{c}\text { Sustainability } \\
\text { level }\end{array}$ \\
\hline CORSAN & 7.49 & & & & & & High \\
\hline CASAN & 10.95 & & & & & & High \\
\hline SANEPAR & 11.54 & & & & & & High \\
\hline COPASA & 12.75 & & & & & & Medium \\
\hline COSANPA & 13.07 & & & & & & Medium \\
\hline SANEAGO & 13.08 & & & & & & Medium \\
\hline CAGEPA & 13.20 & & & & & & Medium \\
\hline CAESB & 13.57 & & & & & & Medium \\
\hline CESAN & 15.43 & & & & & & Medium \\
\hline EMBASA & 15.62 & & & & & & Medium \\
\hline CEDAE & 16.87 & & & & & & Medium \\
\hline COMPESA & 17.06 & & & & & & Medium \\
\hline MA & 18.45 & & & & & & Medium \\
\hline SABESP & 18.48 & & & & & & Medium \\
\hline CAERN & 20.00 & & & & & & Medium \\
\hline CASAL & 20.09 & & & & & & Medium \\
\hline CAEMA & 20.65 & & & & & & Medium \\
\hline AGESPISA & 22.65 & & & & & & Low \\
\hline CAGECE & 23.50 & & & & & & Low \\
\hline DESO & 24.10 & & & & & & Low \\
\hline
\end{tabular}

Figure 4. WWTC's sustainability synthetic indicator (SSIS), their ranking for each sector, and sustainability level. Green circles refer from $1^{\text {st }}$ to $7^{\text {th }}$ position, yellow circles from $8^{\text {th }}$ to $13^{\text {th }}$, and red circles from $14^{\text {th }}$ to $20^{\text {th }}$. Sustainability levels according to Table 2 . 
Figure 4 is self-explanatory and avoids repetitive features providing a long and exhaustive discussion. The top two ranked WWTCs and the one with worse overall performance are presented with details. CORSAN is the WWTC with the highest overall sustainability level, despite the $8^{\text {th }}$ place in sector 1 (environment providing resources) and $12^{\text {th }}$ place in its relationship with sector 2 (environment receiving residues). It is realized that CORSAN's $1^{\text {st }}$ overall sustainability position mainly supports its high economic and social performances. While CORSAN obtained high performance for indicators within sectors 4, 5, and 6, results indicate that practices regarding prevention of water loss (indicator $\mathrm{K}_{11}$ ) should be implemented and better water and wastewater treatment (K12 indicator) to achieve better performance for sector $1 . \mathrm{CO}_{2}$ emissions from sewage (indicator $\mathrm{K}_{21}$ ) and/or the use of electricity (indicator $\mathrm{K}_{22}$ ) should also receive attention for improvements through the application of cleaner production practices (Spriet et al., 2020; Argalis et al., 2021). CORSAN's $1^{\text {st }}$ place in sector 3 indicates that its net profit and the gross value added are obtained at the expense of the environment (sectors 1 and 2), and the $7^{\text {th }}$ and $6^{\text {th }}$ places in sectors 4 and 5, respectively, indicate that the company's relationships with employees and consumers are among the best of all companies. The company keeps a balance between the need to offer decent work (sector 4) and economic growth (sector 3) while providing the proper quantity of water for consumption (sector 5).

CASAN WWTC holds the second position in the overall rank. Its indicators show that the number of jobs available $\left(\mathrm{K}_{41}\right)$ and the ratio between salary and profit $\left(\mathrm{K}_{42}\right)$ should receive attention for improvements in sectors 4 and 5. Regarding using the natural capital, CASAN should implement best management practices focused on water loss reduction $\left(\mathrm{K}_{11}\right)$ and better use of the extracted water $\left(\mathrm{K}_{12}\right)$ to improve its sector 1 performance. A desirable management action should be learning with CORSAN about improving its relationship with social capital, while CORSAN should identify how to improve its sector 2 performance by copying CASAN's practices.

DESO WWTC occupies the lowest position in the SSIS ranking, but surprisingly it holds the 6th and 4th positions respectively in sectors 4 and 5, indicating a high performance for social aspects. However, the identified good performance cannot support the poor performance obtained by sectors 1, 2, and 3, leading to a worse overall comparative ranking position for SISS. DESO's managers should focus on improving its relationship with the environment (sectors 1 and 2) and the economic issues (sector 3) related to its activities.

WWTCs that received red labels for one or more sectors should concentrate efforts to identify potential cleaner production actions to achieve better results for the indicators within the red tags, which would allow the achievement of more sustainable and efficient provision of water services. In practice, it is suggested that every 1st ranked company in a given sector should be taken as an example to be followed by all other companies. What are the best performance WWTCs practices that could be copied? For instance, SANEAGO is the best-ranked company for sector 1, while AGESPISA in sector 2, CORSAN in sector 3 , CASAL in sector 4, and MA in sector 5. Thus, these companies comprehend the sectoral benchmark target pursued by all other WWTCs. It is well known that some practical obstacles will hardly allow all WWTCs to operate under the same technical aspects of efficiency, even because the $5 \mathrm{SenSu}$ model is a systemic-based approach. When changing a given element, others would change as well. The proposed benchmark approach can be considered a first and vital exercise to support better decision-making.

Special mention must be given to SABESP since it is by far the largest WWTC regarding the population served (26.296.796 inhabitants; Figure 4). Even though every indicator considered in our analysis is relative to the population served or volumes of potable water and treated sewage - these criteria are used to allow fair comparisons among WWTCs -, the absolute gains are more expressive viewed under the company's size. Thus, any improvement action implemented by SABESP would result in considerable gains in absolute units. This company holds low ranks (from $14^{\text {th }}$ to $19^{\text {th }}$ positions) in sectors 1,4 , and 5 (Figure 4), emphasizing that priority should be made for these sectors for improvements. 
The obtained $3^{\text {rd }}$ position for sector 2 is acceptable and desirable, suggesting how well SABESP deals with $\mathrm{CO}_{2}$ emissions. Finally, SABESP has an intermediary rank position for sector $3\left(11^{\text {th }}\right)$, calling attention to improvements on its net profit and gross value-added indicators.

\subsection{WWTCs and their relation with SDGs}

The 5SenSU model helps decision-makers identify which sectors should be prioritized to improve the companies' contribution to sustainability and highlight improvements in a given sector regarding their contribution to SDG achievement. Establishing trade-offs between the companies' performance and their identified management options with the SDGs revealed some limitations, mainly because of the existing synergies and trade-offs across all SDGs (Nilsson et al., 2016, Pradhan et al., 2017). Anyhow, Table 3 shows how the WWTCs contribute to achieving the SDGs. As an example, according to the criteria presented in Table 1, SDG 3 (good health and wellbeing) is more closely related to indicators $\mathrm{K}_{42}, \mathrm{~K}_{51}$, and $\mathrm{K}_{52}$. Using the Excel® file available in the Supplementary Material A for modeling purposes, only these indicators related to SDG 3 is considered to obtain new SSIS values and ranking WWTCs, allowing to understand which companies are the most contributors for SDG 3; this approach is repeated for each one of the SDGs presented in Table 3 (SDGs 3, 6, 8, 12, 13 and 14). Green circles shown in Table 3 refer to the WWTCs that were comparatively rated as high contributors (high sustainability level) to the achievement of the given SDG.

In contrast, the yellow circles refer to companies that were medium rated (medium sustainability level), and the red ones are those that were low rated (low sustainability level). Visually, there is a correlation between the best ranked WWTC on their SSISs with the achievement of SDGs, in which green-colored circles appear on those most wellranked WWTCs while the red ones appear as a characteristic of lowest-ranked WWTCs. It is essential to mention that Figure 4 and Table 3 show different perspectives because while the former presents an overall analysis based on SSIS values, the latter considers exclusively those indicators that contribute to SDGs in obtaining SSIS. From Table 3, CORSAN (1 ${ }^{\text {st }}$ overall ranked) presents a high contribution to SDGs 6 and 8 while giving a moderate contribution to $3,12,13$, and 14 . On the other hand, DESO (20 th overall ranked) presents a low contribution to SDGs $6,12,13$, and 14, medium contribution to SDG 8, but a high contribution to SDG 3. These peculiarities must be carefully assessed since the $5 \mathrm{SenSu}$ is a multicriteria approach characterized by trade-offs between environmental, economic, and social sectors. When considering only those indicators that influence a given SDG (as presented by Table 3), results are different compared to the SSIS obtained by considering all ten indicators simultaneously (Figure 3). This different perspective for management when assessing systems performance is an important contribution of the 5SenSu model.

The potential of the Brazilian WWTCs in contributing to the SDGs seems not to be related to the company's size as represented by the population attended. Considering the provision services, WWTC's activities are mainly related to SDG 6 (clean water and sanitation). However, access to clean water is a necessary condition for achieving other SDGs, such as SDG 1 (no poverty), SDG 2 (zero hunger), and SDG 11 (sustainable cities and communities) that partially imply providing safe drinking water to people (Le Blanc, 2015). Similarly, SDG 3 (good health and wellbeing) is highly dependent on SDG 6, being safe water sources and sanitation key factors for improving health and quality of life. Concerning the ecosystem's regulatory services, SDG 14 (life below water) on preserving marine and freshwater life relates to SDG 6 as it concerns activities with potential impacts on these very same ecosystems. WWTCs usually operate with intense greenhouse gas emissions. Thus, it is crucial to address the trade-offs between SDG 6 and SDG 13 (climate action; Zhang et al., 2011). Additionally, as a human-made utility dedicated to causing lower load on the natural environment, especially nature's regulatory ecosystem services, WWTCs also contribute to SDG 8 (decent work and economic growth) that includes employment 
goals and progressing towards SDG12 (responsible consumption and production) on responsible water consumption and keeping good engineering practices within its production process (Doswald et al., 2011). Focusing on studies towards more sustainable production or operation of WWTCs, the literature offers several options to adopt cleaner production practices that may improve the water supply and treatment systems (Wolf et al., 2015; Bello et al., 2017; Kurniawan et al., 2021; Waqas et al., 2021; Kong et al., 2019).

Table 3. WWTCs ranked according to SSIS, their population attended, and contribution to achieving some SDGs.

\begin{tabular}{|c|c|c|c|c|c|c|c|}
\hline \multirow{3}{*}{ WWTC a } & \multirow{3}{*}{$\begin{array}{l}\text { Population at- } \\
\text { tended }\end{array}$} & \multicolumn{6}{|c|}{ Relationship among indicators and SDGs $b$} \\
\hline & & $\mathbf{K}_{42}, \mathbf{K}_{51}, \mathbf{K}_{52}$ & All indicators & $\begin{array}{c}\mathbf{K}_{31}, \mathbf{K}_{32,} \mathbf{K}_{41}, \\
\mathbf{K}_{42}\end{array}$ & $\mathrm{~K}_{11}, \mathrm{~K}_{12}, \mathrm{~K}_{51}$ & $\mathbf{K}_{21}, \mathbf{K}_{22}$ & $\mathbf{K}_{12}, \mathbf{K}_{52}$ \\
\hline & & 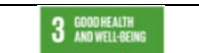 & 6 a & 88 & 12 & $13^{\text {aland }}$ & 14 tef \\
\hline CORSAN & $6,196,640$ & - & - & - & - & - & - \\
\hline CASAN & $2,659,809$ & - & $\bullet$ & - & - & - & - \\
\hline SANEPAR & $8,807,262$ & - & $\bullet$ & - & - & - & - \\
\hline COPASA & $12,438,532$ & $\bullet$ & $\bullet$ & $\bullet$ & - & - & - \\
\hline COSANPA & $3,938,416$ & - & $\bullet$ & • & - & - & - \\
\hline SANEAGO & $5,497,840$ & - & - & - & - & - & - \\
\hline CAGEPA & $2,776,732$ & $\bullet$ & $\bullet$ & - & - & - & $\bullet$ \\
\hline CAESB & $2,754,765$ & - & - & - & - & - & - \\
\hline CESAN & $2,369,378$ & - & - & - & - & - & - \\
\hline EMBASA & $9,650,459$ & - & - & - & - & - & $\bullet$ \\
\hline CEDAE & $13,112,006$ & - & $\bullet$ & - & $\bullet$ & - & $\bullet$ \\
\hline COMPESA & $7,231,208$ & - & $\bullet$ & - & - & - & - \\
\hline MA & $2,010,062$ & - & - & - & - & $\bullet$ & - \\
\hline SABESP & $26,296,796$ & $\bullet$ & - & - & - & - & $\bullet$ \\
\hline CAERN & $2,429,972$ & $\bullet$ & - & - & - & - & - \\
\hline CASAL & $1,960,988$ & • & - & - & - & $\bullet$ & - \\
\hline CAEMA & $3,128,332$ & - & - & - & - & - & $\bullet$ \\
\hline AGESPISA & $1,952,368$ & - & • & • & - & - & - \\
\hline CAGECE & $5,862,595$ & - & $\bullet$ & $\bullet$ & • & - & $\bullet$ \\
\hline DESO & $1,605,371$ & - & - & - & - & - & • \\
\hline
\end{tabular}

a Ranked according to SSIS values of Figure 4. ${ }^{\mathrm{s}}$ SDG 3, good health and wellbeing; SDG 6, clean water and sanitation; SDG 8, decent work and economic growth; SDG 12, responsible consumption and production; SDG 13, climate action; SDG 14, life below water. Indicators related to every SDG are the same as in Table 1 last column.

\section{Discussion}

It would not be very objective to cogitate that management of water resources can occur without involving the natural environment and their synergic relationship since sustainable development is hopefully becoming part of conventional wisdom. Historically, when water resources were abundant, and their demand was lower, the role of WWTCs in helping people's livelihoods has received little consideration. Priority was given to social and economic development. The impact of water demand on the natural environment was neglected because biocapacity was enough to supply water needs by humans and dilute pollutants in the wastewater. However, the water demand is growing fast, exceeding biocapacity in many regions worldwide, especially for developing countries that need to better manage their water resource to achieve better socioeconomic performance indicators. The worst scenario happens when water resources are unavailable due to natural conditions or when water storage is poorly managed. While humans can 
hardly address the first issue, the second one can become of paramount importance, as discussed in this present study, providing alternative ways to identify aspects that should receive priorities for actions to achieve more sustainable water resources management.

Rather than using conventional techniques to deal with water supply/treatment usually based on technical-economic perspectives, the WWTCs should be managed to synergically operate with the natural environment under a systemic approach, as a provider or receiver function (sectors 1 and 2). Decision-makers must recognize the natural environment for a more rational course of action. Still, it is not hard to find WWTCs - at least in Brazil - that disregard this systemic approach for management, maybe due to a lack of knowledge about its importance and methods in obtaining quantitative indicators.

Engineering and technological interventions around ecosystems can add to uncertainties since any decision involving trade-offs of ecosystem service involves valuation (Costanza et al., 2014; Burke et al., 2015). There are different values in the relationship between human and non-human nature, depending on how and where the concept is operationalized and implemented (Jax et al., 2013) and the assembly of economic values associated with various WWTC options. Anyhow, decision-makers should pay attention to the cost of losing a service, which may incorporate the cost of supplementary technologies to allow the services to continue - when possible - since the impacts on water quality and quantity can threaten water security.

This work contributes to the disclosure of existing trade-offs between the WWTCs and the 5 SenSu model sectors, which can be considered important to identify the strengths and weaknesses of each WWTC that should receive priorities for actions towards a cleaner, more sustainable operation. Comparative indicators from other higher performance WWTCs can be used as a benchmark for this task. Besides a powerful tool for management, the assessment of WWTCs under the 5SenSu allows identifying how far or close WWTCs are to the SDGs goals. The model helps companies track their relative sustainability level across similar companies while highlighting their contributions to society, economy, and natural capital preservation to maintain ecosystem services provision to deal with the high demands of the present society.

\section{Conclusions}

Pressure on the natural environment is increasing due to population growth and lifestyles, which claims for all-inclusive management approaches towards natural resources (including water) security to avoid overconsumption and environmental load that would risk societal development. Although ecosystem services perception can conceptually offer a practical approach to highlight the man-nature relationship, WWTCs management has been obstructed by the lack of suitable models and methods. From a systemic perspective for sustainability, the 5SenSu model was considered to assess WWTCs as an alternative to offer more precise indication for decision-makers about systems performance on different environmental, economic and social indicators. Applying the 5SenSu model into the twenty largest WWTCs in Brazil allowed us to rank them according to their sustainability level, besides highlighting the sectors where improvements are imperative to achieve management strategies more aligned to the SDGs. From a general perspective, the top three SSIS-ranked WWTCs named as CORSAN, CASAN, and SANEPAR should be considered as examples of best practices to be followed by all others WWTCs, while those best-ranked companies in each sector (SANEAGO, sector 1; AGESISA, sector 2; CORSAN, sector 3; CASAL, sector 4; MA, sector 5) should be used as benchmark patterns for more oriented best practices. The disclosure of trade-offs between the WWTC and the environment highlights the opportunities for decision-makers learning among the various options and preventing the risk of adopting poorly adapted investments regarding the best provision of shared water resources.

The 5SEnSU allowed identifying those WWTCs companies that adopt the best currently available practices for their operation, which leads to a stronger relationship with the environment, society, and economic capitals. Specifically, their cleaner production 
practices are related to water savings, improving distribution efficiency, investments to reduce greenhouse gas emissions, and increasing the quantity and quality of jobs. The multidimensional assessment of the trade-offs among sectors may assist in supporting decision-making to incorporate, beyond the traditional financial capital, other important aspects related to sustainability such as preserving the natural wealth to help the provision and regulation of ecosystem services and social issues. In this context, the 5SEnSU model can be an alternative in pushing company decision-makers to implement practices in line with the UN SDGs by understanding the relationships among the five sectors that can lead to interventions for human prosperity while helping to keep natural ecosystems healthy.

Acknowledgments: The authors wish to thank the Vice-Reitoria de Pós-graduação of Paulista Univesity (UNIP). RRMG is grateful to scholarship provided by Coordenação de Aperfeiçoamento de Pessoal de Ensino Superior (CAPES, process number 433442-2016-6). FA recognizes the support from CNPq Brasil (proc. 307422/2015-1). The authors are also grateful to the Beijing Normal University for China's National High-end Foreign Experts Recruitment Program. LC was funded by an IRC/Marie Skłodowska-Curie CAROLINE Postdoctoral Fellowship (IRC-CLNE/2017/567).

Appendix A.

Table A1. Indicators, goals and objectives (based on the 5SenSu model) considered for the assessed water and wastewater treatments companies (WWTCs). The automatized calculation procedure is available at Supplementary Material A as Excell® spreadsheet.

\begin{tabular}{|c|c|c|c|c|c|c|c|c|c|c|}
\hline \multirow{2}{*}{ WWTC } & \multicolumn{2}{|c|}{ Sector 1} & \multicolumn{2}{|c|}{ Sector 2} & \multicolumn{2}{|c|}{ Sector 3} & \multicolumn{2}{|c|}{ Sector 4} & \multicolumn{2}{|c|}{ Sector 5} \\
\hline & $K_{11}{ }^{a}$ & $K_{12}{ }^{a}$ & $K_{21}{ }^{a}$ & $K_{22}{ }^{a}$ & $K_{31}{ }^{a}$ & $K_{32}{ }^{a}$ & $\mathrm{~K}_{41} \mathrm{a}^{\mathrm{a}}$ & $K_{42}{ }^{a}$ & $\mathrm{~K}_{51}{ }^{\mathrm{a}}$ & $\mathrm{K}_{52}{ }^{\mathrm{a}}$ \\
\hline CORSAN & 0.315 & 0.084 & 4.825 & 0.171 & 0.208 & 1.500 & 17.128 & 0.458 & 135.74 & 0.911 \\
\hline CASAN & 0.397 & 0.095 & 3.362 & 0.123 & 0.101 & 0.835 & 11.670 & 0.435 & 184.37 & 0.803 \\
\hline SANEPAR & 0.325 & 0.083 & 3.588 & 0.144 & 0.126 & 0.588 & 7.640 & 0.419 & 168.14 & 0.843 \\
\hline COPASA & 0.336 & 0.077 & 4.539 & 0.165 & 0.082 & 0.719 & 11.096 & 0.371 & 151.92 & 0.538 \\
\hline COSANPA & 0.459 & 0.039 & 3.681 & 0.269 & 0.232 & 0.270 & 13.143 & 1.343 & 122.01 & 0.072 \\
\hline SANEAGO & 0.286 & 0.070 & 4.332 & 0.162 & -0.037 & 0.810 & 12.389 & 0.492 & 140.80 & 0.904 \\
\hline CAGEPA & 0.388 & 0.081 & 4.309 & 0.210 & -0.017 & 0.656 & 17.468 & 0.662 & 130.01 & 1.080 \\
\hline CAESB & 0.271 & 0.091 & 3.328 & 0.171 & 0.008 & 0.934 & 7.542 & 0.610 & 184.41 & 0.820 \\
\hline CESAN & 0.330 & 0.106 & 3.126 & 0.098 & 0.113 & 0.532 & 5.925 & 0.344 & 246.68 & 0.785 \\
\hline EMBASA & 0.404 & 0.074 & 4.219 & 0.178 & 0.026 & 0.609 & 6.560 & 0.346 & 135.29 & 0.955 \\
\hline CEDAE & 0.306 & 0.142 & 4.247 & 0.160 & 0.110 & 0.924 & 5.433 & 0.218 & 203.55 & 1.006 \\
\hline COMPESA & 0.519 & 0.082 & 4.074 & 0.225 & 0.083 & 0.520 & 8.290 & 0.392 & 134.49 & 0.836 \\
\hline MA & 0.493 & 0.108 & 5.234 & 0.318 & 0.121 & 0.986 & 9.533 & 0.187 & 105.27 & 3.242 \\
\hline SABESP & 0.314 & 0.108 & 3.378 & 0.130 & 0.072 & 0.519 & 4.074 & 0.328 & 216.29 & 0.547 \\
\hline CAERN & 0.558 & 0.096 & 4.392 & 0.238 & 0.009 & 0.602 & 13.837 & 0.472 & 136.98 & 0.622 \\
\hline CASAL & 0.448 & 0.078 & 6.731 & 0.297 & 0.000 & 0.444 & 14.713 & 0.924 & 96.68 & 0.886 \\
\hline CAEMA & 0.622 & 0.094 & 3.740 & 0.228 & -0.046 & 0.459 & 15.426 & 0.974 & 125.34 & 0.382 \\
\hline AGESPISA & 0.517 & 0.103 & 3.919 & 0.159 & -0.177 & 0.425 & 11.492 & 1.106 & 159.73 & 0.715 \\
\hline CAGECE & 0.424 & 0.066 & 4.049 & 0.098 & -0.197 & 0.437 & 4.613 & 0.433 & 169.58 & 0.862 \\
\hline DESO & 0.608 & 0.122 & 3.910 & 0.313 & -0.046 & 0.625 & 12.757 & 0.677 & 143.55 & 1.000 \\
\hline Goal & 0.3794 & 0.061 & 3.932 & 0.165 & 0.148 & 0.944 & 14.67 & 0.866 & 110.00 & 1.493 \\
\hline Objective & Minimize & Minimize & Minimize & Minimize & Maximize & Maximiz & Maximize & Maximiz & Maximize & Maximiz \\
\hline
\end{tabular}

${ }^{a}$ For indicators description, please refer to Table 1 within the main text. ${ }^{b}$ Punishments used in the goal programming were set as 0.2 (highest) and 100 (lowest) according to goal programming algebra and the standard values considered by Giannetti et al. (2019).

\section{References}

Argalis, PP; Vegere, K. Perspective Biomethane Potential, and Its Utilization in the Transport Sector in the Current Situation of Latvia. Sustainability 2021, 13, 7827. https://doi.org/10.3390/su13147827

Bello, M.M., Abdul Raman, A.A., Purushothaman, M. Applications of fluidized bed reactors in wastewater treatment - A review of the major design and operational parameters. Journal of Cleaner Production, 2017, 141, 1492-1514 
Björklund, J.; Geber, U.; Rydberg, T. Emergy analysis of municipal wastewater treatment and generation of electricity by digestion of sewage sludge. Resour. Conserv. Recycl, 2001, 31, 293-316. https://doi.org/10.1016/S0921-3449(00)00091-4

Burke, L., Ranganathan, J., Winterbottom, R. (Eds). Revaluing Ecosystems: Pathways for Scaling Up the Inclusion of Ecosystem Value in Decision Making. World Resources Institute, Washington, DC, USA. Available at: https://static1.squarespace.com/static/57e1f17b37c58156a98f1ee4/t/58112ee3414fb5b9a08006b3/1477521124634/Revaluing_Ecosystems_April_2015_2_ENG.pdf, 2015 Last accessed on May 2021.

Costanza, R., de Groot, R., Sutton, P., van der Ploeg, S., Anderson, S.J., Kubiszewski, I., Farber, S., Turner, R.K., Changes in the global value of ecosystem services. Glob. Environ. Change, 2014, 26, 152-158. https://doi.org/10.1016/j.gloenvcha.2014.04.002

De Jongh, J., Mncayi, P., Mdluli, P. Analysing the impact of water access and sanitation on local economic development (LED) in the Sedibeng District Municipality, South Africa. International Journal of Innovation, Creativity and Change, 2019, 5(2), 551-572.

Doswald, N., Osti, M. Ecosystem-based Approaches to Adaptation and Mitigation - Good Practice Examples and Lessons Learned in Europe. Federal Agency for Nature Conservation (BfN), Bonn, Germany. Available at: http://www.naturathlon.info/fileadmin/BfN/service/Dokumente/skripten/Skript306.pdf, 2011. Last accessed on Junne 2021.

Giannetti B.F., Silva C.C., Agostinho F., Almeida, CMVB Emergy evaluation of domestic wastewater treatments: the role of energy and materials consumption and carbon emissions. J. Environ. Account. Manag., 2013, 4(3), 317-338. https://doi.org/10.5890/JEAM.2016.09.006

Giannetti, B. F., Agostinho, F., Almeida, C. M. V. B., Liu, G., Contreras, L. E. V., Vandercasteele, C., Coscieme, L., Sutton, P., Poveda, C. Insights on the United Nations Sustainable Development Goals scope: Are they aligned with a 'strong' sustainable development? J. Clean. Prod., 2020, 252, 119574. https://doi.org/10.1016/j.jclepro.2019.119574

Giannetti, B. F., Sevegnani, F., Almeida, C. M. V. B., Agostinho, F., García, R. R. M., Liu, G. Five sector sustainability model: A proposal for assessing sustainability of production systems. Ecol Model., 2019, 406, 98-108.

Huttenhower, C., Gevers, D., Knight, R., Wilson, R.K., White, O. Structure, function and diversity of the healthy human microbiome. Nature, 2012, 486, 207-214. https://doi.org/10.1038/nature11234

Jax, K., Barton, D.N., Chan, K.M.A., de Groot, R., Doyle, U., Eser, U., Görg, C., Gómez-Baggethun, E., Griewald, Y., Haber, W., Haines-Young, R., Heink U., Jahn, T., Joosten, H., Kerschbaumer, L., Korn, H., Luck, G.W., Matzdorf, B., Muraca, B., Neßhöver, C., Norton, B., Ott, K., Potschin, M., Rauschmayer, F., von Haaren, C., Wichmann, S. Ecosystem services and ethics. Ecol. Econ.,2013, 93, 260-268. https://doi.org/10.1016/j.ecolecon.2013.06.008

Johnston, R.; Buchanan, J. Understanding productivity in Northern Ireland. Ulster University Economic Policy Centre. Available at: https://www.ulster.ac.uk/_data/assets/pdf_file/0008/118385/Understanding_productivity_in_Northern_Ireland_27_September_2016.pdf, 2016. Last accesses on March 2021

Kong, Z., Li, L., Xue, Y., Yang, M., Li, Y.-Y. Challenges and prospects for the anaerobic treatment of chemical-industrial organic wastewater: A review. Journal of Cleaner Production, 2019, 231, 913-927

Kurniawan, S.B., Ahmad, A., Said, N.S.M., Purwanti, I.F., Hasan, H.A. Macrophytes as wastewater treatment agents: Nutrient uptake and potential of produced biomass utilization toward circular economy initiatives. Science of the Total Environment, 2021, 790,148219

Le Blanc, D. Towards Integration at Last? The Sustainable Development Goals as a Network of Targets. Sustainable Development, 2015, 23, 176-187. https://doi.org/10.1002/sd.1582

Liu, G., Yang, Z., Chen, B., Zhang, J., Liu, X., Zhang, Y., Su, M., Ulgiati, S. Scenarios for sewage sludge reduction and reuse in clinker production towards regional eco-industrial development: a comparative emergy-based assessment. J. Clean. Prod., 2015, 103, 371-383. https://doi.org/10.1016/j.jclepro.2014.09.003

Marques R.C., Cruz N. F., Pires J. Measuring the sustainability of urban water services. Environ Sci Policy, 2015, 54, 142-151. https://doi.org/10.1016/j.envsci.2015.07.003

Mirabia M., Mianabadi H., Zarghami M., Sharifia M. B., Mostert E. Risk-based evaluation of wastewater treatment projects: A case study in Niasar city, Iran. Resour. Conserv. Recy., 2014, 93, 168-177. https://doi.org/10.1016/j.resconrec.2014.10.002

Molinos-Senante M., Marques R.C., Pérez F., Gómez T., Sala-Garrido R., Caballero R. Assessing the sustainability of water companies: A synthetic indicator approach. Ecol. Indic., 2016, 61, 577-587. https://doi.org/10.1016/j.ecolind.2015.10.009

Nematian, J., Movahhed, S. R. An extended multi-objective mixed integer programming for water resources management through possibility theory. Ecol. Inform, 2019, 54: 100992. https://doi.org/10.1016/j.ecoinf.2019.100992

Nilsson, M.; Griggs, D.; Visbeck, M. Map the interactions between Sustainable Development Goals. Nature, 2016, 534, $320-322$. https://doi.org/10.1038/534320a

Odum, H. T. Environmental accounting - Emergy and environmental decision making, John Wiley \& Songs Ltd, New York, 1996.

Postel, S.L. Securing water for people, crops, and ecosystems: New mindset and new priorities. Nat. Resour. Forum., 2003, 27(2), 8998. https://doi.org/10.1111/1477-8947.00044

Pradhan, P.; Costa, L.; Rybski, D.; Lucht, W.; Kropp, J. P. A Systematic Study of Sustainable Development Goal (SDG) Interactions. Earth's Future, 2017, 5(11), 1169-1179. https://doi.org/10.1002/2017EF000632

Sanitation, Hot Water Safety - HM Government (2010) available at: https://assets.publishing.service.gov.uk/government/uploads/system/uploads/attachment_data/file/504207/BR_PDF_AD_G_2015_with_2016_amendments.pdf

SNIS, National Information System about Sanitation, 2014. http://www.snis.gov.br/ last access: 19/09/2018.Last accessen on August 2021. 
Spriet, J., McNabola, A., Neugebauer, G., Ertl, T., Kretschmer, F.Spatial and temporal considerations in the performance of wastewater heat recovery systems. Journal of Cleaner Production, 2020, 247,119583 Analysing the impact of water access and sanitation on local economic development (LED) in the Sedibeng District Municipality, South Africa De Jongh, J., Mncayi, P., Mdluli, P. 2019 International Journal of Innovation, Creativity and Change 5(2), pp. 551-572

United Nations, 2015. The United Nations World Water Development Report 2014 - Water and Energy Volume 1. Available at: https://www.unwater.org/publications/world-water-development-report-2014-water-energy/, Last accessed on February 2021.

United Nations, 2015. Transforming our World: The 2030 Agenda for Sustainable Development. Available at: https://sustainabledevelopment.un.org/post2015/transformingourworld/publication. Last accessed on February 2021.

Vassallo, P.; Paoli, C.; Fabiano, M. Emergy required for the complete treatment of municipal wastewater. Ecol. Eng., 2009, 35, 687694. https://doi.org/10.1016/j.ecoleng.2008.11.002

Waqas, S., Bilad, M.R., Man, Z.B., Dzarfan Othman, M.H., Elma, M. An energy-efficient membrane rotating biological contactor for wastewater treatment. Journal of Cleaner Production, 2021, 282,124544

Wolff, E., Schwabe, W.K., Conceição, S.V. Utilization of water treatment plant sludge in structural ceramics. Journal of Cleaner Production, 2015, 96,4413, 282-289New investment, old challenges. Land deals and the water constraint in African agriculture Woodhouse, P. 2012 Journal of Peasant Studies 39(3-4), pp. 777-794

Woodhouse, P. New investment, old challenges. Land deals and the water constraint in African agriculture. J. Peasant Stud., 2012, 39(3-4), 777-794. https://doi.org/10.1080/03066150.2012.660481

World Health Organization - Domestic Water Quantity, Service, Level and Health, 2003. Available at: https://www.who.int/water_sanitation_health/diseases/WSH03.02.pdf. Last accessed on May 2021.

Zhang, Q.; Liu, S.; Wang, T.; Dai, X.; Baninla, Y.; Nakatani, J.; Moriguchi, Y Urbanization impacts on greenhouse gas (GHG) emissions of the water infrastructure in China: Trade-offs among sustainable development goals (SDGs). J. Clean. Prod., 2019, 232, 474486. https://doi.org/10.1016/j.jclepro.2019.05.333

Zhang, X.; Deng, S.; Wu, J.; Jiang, W. A sustainability analysis of a municipal sewage treatment ecosystem based on emergy. Ecol. Eng., 2010, 36, 685-696. https://doi.org/10.1016/j.ecoleng.2009.12.010

Zhang, X.; Wei, Y.; Pan, H.; Xiao H.; Wu, J.; Zhang, Y. The comparison of performances of a sewage treatment system before and after implementing the cleaner production measure. J. Clean. Prod., 2015, 91, 216-228. https://doi.org/10.1016/j.jclepro.2014.12.025 